\title{
Nutritional Effects of Three Mulberry Varieties on Silkworms in Torbat Heydarieh
}

\author{
Masoud Alipanah $\left(\mathbb{D},{ }^{1}\right.$ Zabihollah Abedian, ${ }^{2}$ Abdolazim Nasiri, ${ }^{2}$ and Farid Sarjamei ${ }^{2}$ \\ ${ }^{1}$ University of Torbat Heydarieh, Department of Plant Science, Torbat Heydarieh, Iran \\ ${ }^{2}$ Sericulture Center of Khorasan Razavi, Torbat Heydarieh, Iran \\ Correspondence should be addressed to Masoud Alipanah; m.alipanah@torbath.ac.ir
}

Received 6 February 2020; Revised 26 April 2020; Accepted 6 May 2020; Published 29 May 2020

Academic Editor: Cleber Galvão

Copyright (c) 2020 Masoud Alipanah et al. This is an open access article distributed under the Creative Commons Attribution License, which permits unrestricted use, distribution, and reproduction in any medium, provided the original work is properly cited.

\begin{abstract}
This research was conducted to evaluate and compare the performance of the silkworm hybrid $p 31 \times p 32$ reared with three varieties of mulberry leaves. In this study, the silkworms were fed with leaves from Kenmochi (Morus bombycis), native mulberry (Morus alba L.), and black mulberry (Morus nigra L.) trees and their influence on the leaf ingested, leaf digested, cocoon weight, efficiency of feed consumption to cocoon shell, efficiency of digested feed to cocoon shell weight, efficiency of digested feed to cocoon weight, and efficiency of feed consumption to cocoon weight was studied in the Torbat Heydarieh region. The results showed that silkworms that consumed leaves of Kenmochi had better performance. Also, they had better performance for traits of cocoon shell weight, feed efficiency to cocoon shell weight, and feed efficiency to cocoon weight. Therefore, Kenmochi tree is suggested for development of sericulture in the region.
\end{abstract}

\section{Introduction}

Silkworm is a very important economic insect which contributes substantially to the national economy and gross domestic production (GDP) of many countries such as China, India, and Thailand [1]. Iran has about 14,000 hectares of area under mulberry cultivation, and sericulture in these areas has provided employment and income generation for more than 60,000 households [2]; it is the fifth cocoon-producing country and the seventh silk-producing country in the world [3]. Mulberry leaves are the only food source for silkworms (Bombyx mori L.). Mulberry tree is grown under varied climatic conditions, ranging from temperate to tropical; hence, the growth and development as well the quality and quantity of cocoons produced are largely influenced by leaf quality [4]. Leaves with higher nutrient quality not only increase the quality of production but also help the insect to resist diseases. Due to climatic changes and droughts and decreasing tendency to plant and grow mulberry trees in different areas, there is a need to research the varieties adapted to new environmental conditions.
Differences in the performances of silkworms fed with different varieties of mulberry trees have been studied by a number of researchers [5-7]. In the present study, the effect of feeding of leaves from three varieties of mulberry trees including Kenmochi (Morus bombycis Kodiz), black berry (Morus nigra L.), and native mulberry (Morus alba L.) on production quality of silkworms (B. mori) has been considered.

\section{Methodology}

2.1. Animals and Experiment. The eggs of hybrid p31×p32 silkworms were obtained from Iran Silkworm Rearing Co. (Rasht, Iran) and reared in the Torbat Heydarieh sericulture center (Torbat Heydarieh, Iran) under a standard condition of $25 \pm 5^{\circ} \mathrm{C}$ with a $\mathrm{RH}$ of $80 \pm 5 \%$ and a photoperiod of $16 \mathrm{~L}: 8 \mathrm{D}$ as described by Hosseini [8]. The larvae were fed with mulberry leaves of Kenmochi variety up to the 5 th instar. The first and second instar larvae were fed with chopped green leaves while for the remaining three instar larvae, whole leaves were fed. 
After third instar, silkworms were reared on leaves of three mulberry varieties separately. Mulberry varieties included the following: Kenmochi (M. bombycis), native mulberry (M. alba), and black mulberry ( $M$. nigra) trees. Fourth instar larvae were divided into 3 experimental groups, with three replicates in each group. Each replicate consisted of 300 healthy larvae of uniform size and age. To replace the dead and unequal larvae, a separate group of worms were maintained under identical conditions.

In order to determine nutritional parameters, leaf weight, residual leaf weight, excreta weight, cocoon weight, cocoon shell weight, and cocoon shell percentage were measured. All the weights noted in this study are based on dry weight. Nutritional parameters such as efficiency of conversion of ingested food (ECI) and efficiency of conversion of digested food (ECD) by the larva were calculated by the method described Muniraju et al. [9].

Collected data were subjected to statistical analysis of variance for significant differences in the measured groups of parameters. For all analyses of variance, Duncan's multiple range test in general linear model (GLM) procedure of SAS 9.2 software was used.

\section{Results and Discussion}

The results of performances and nutritional indices of the silkworms are presented in Tables 1-3. Based on these results, the performance of ingested Kenmochi leaves was significantly lower than that of the blackberry and native tree leaves $(P<0.05)$. The results also showed that the excreta weight of silkworms that consumed the leaves of the black berry and native trees was the highest $(P<0.05)$. Based on the weight of the leaves consumed and the excreta weight, the digested feed weight was the highest in silkworms feeding on Kenmochi leaves $(P<0.05)$. According to the content of dry matter in the three varieties of mulberry, it is possible to observe that there is a relationship between dry matter content of leaves and digested weight of the leaf. The study of Rahmathulla et al. [10] indicated that nutritional parameters such as ingesta, digesta, approximate digestibility, reference ratio, and consumption index were significantly higher in silkworm that were fed with leaves of higher moisture content. Other researchers have emphasized the direct effect of mulberry leaf quality on food intake [11].

As expected, results presented in Table 1 show that ingestability (\%) in Kenmochi experimental thesis was the lowest $(P<0.05)$, while digestibility of leaves of the Kenmochi variety being $54.79 \%$ was highest and digestibility for black berry leaves was very low, being only $37.10 \%$ $(P<0.05)$. These traits probably were affected by the moisture content of leaves; these results are consistent with previous result reports: for example, one previous research showed that up to $70 \%$ leaf moisture, all the nutritional indices increased progressively with an increase in the moisture level of leaves [11].

The survival of larvae up to the cocoon stage was in three experimental theses (Kenmochi, native, and black berry), respectively: 95.67, 90.00, and 88.67. Therefore, there were significant differences among treatments. There was a significant difference for total cocoon weight $(P<0.05)$; in fact, the Kenmochi treatment produced $152.09 \mathrm{~g}$ of cocoons showing the highest weight with respect to all the treatments, while the total cocoon weight for native and black berry tree was $135.13 \mathrm{~g}$ and $125.71 \mathrm{~g}$, respectively. The best cocoon weight for 1000 larvae was observed $(P<0.05)$ when insects were fed with Kenmochi leaves while the lowest weight was recorded on black berry leaves (Table 2). Cocoon weight is one of the most important economic characteristics of silkworms, especially in Iran where product marketing is based on the cocoon weight. In general, mulberry varieties have to be modified and selected to produce the silkworm cocoons as heavy as possible [12]. Larval weight is another important trait in sericulture: larval weight is highly influenced by various environmental factors such as feeding and rearing environment and, on the other hand, larval weight has a significant correlation with cocoon weight, pupa weight, and silk shell weight [13].

Shell percentage was the highest in the treatments with Kenmochi and the native mulberry tree in comparison with black berry treatment $(P<0.05)$ (Table 3$)$. The ECI for cocoon production and cocoon shell percentage significantly differs among treatments, and two traits were the highest in the Kenmochi treatment with 14.29 and 9.02, respectively. But native and black berry treatments were not different for shell percentage ECI and cocoon ECI. The research findings are in agreement with the work of $[14,15]$ who concluded that low nutritional indices in native tree leaves can be due to the low moisture content and harsh physical structure of their mulberry leaves.

The results of different researchers revealed that the content of mulberry leaves consumed caused differences in the performances of silkworm larvae. For example, in the study of Rajabi Kanafgorabi et al. [15], there was a significant difference in the yield of treatments fed with Kokuso and native mulberry varieties.

The cocoon weight was introduced as the best parameter to evaluate the nutritional effect of different varieties of mulberry [16]. Our results showed that the total cocoon weight was higher $(P<0.05)$ for silkworms treated with Kenmochi leaves $(P<0.05)$.

Motahari et al. [12] reported that the weight gained in silkworms that were fed with native leaves was the lowest in comparison to other tree leaves. In another study comparing different mulberry trees, it was found that mulberry variety had a significant effect on silkworm weight performance [17]. Comparison between performances of silkworm fed with different mulberry varieties showed that the highest number of cocoons was obtained when the leaves of Wasemidori and Kenmochi cultivars were used [12].

In general, it can be said that the variation in measured traits for silkworms fed with different tree leaves is due to different chemical compositions of the leaves. Differences in the performance of silkworms fed with different berry varieties have been documented in the results of many research studies [18-20].

Based on the results of the present study, it was observed that leaves of Kenmochi tree supported good growth and development of silkworm, which is reflected in higher 
TABLE 1: Mean of leaf ingesta and digesta parameters of silkworm hybrid treated with three varieties of mulberry leaves.

\begin{tabular}{lcccccc}
\hline Tree variety & Dry matter (\%) & Leaf ingested (g) & Excreta weight (g) & Leaf digested (g) & Ingestability (\%) & Digestibility (\%) \\
\hline Kenmochi & 32 & $4.55^{\mathrm{a}}$ & $2.06^{\mathrm{a}}$ & $2.49^{\mathrm{a}}$ & $61.91^{\mathrm{a}}$ & $54.79^{\mathrm{a}}$ \\
Native & 34 & $5.39^{\mathrm{b}}$ & $3.22^{\mathrm{b}}$ & $2.17^{\mathrm{b}}$ & $69.03^{\mathrm{b}}$ & $40.25^{\mathrm{b}}$ \\
Black berry & 36 & $5.53^{\mathrm{b}}$ & $3.48^{\mathrm{c}}$ & $2.05^{\mathrm{b}}$ & $68.84^{\mathrm{b}}$ & $37.10^{\mathrm{c}}$ \\
Mean \pm SE & $34 \pm 1.15$ & $5.16 \pm 0.11$ & $2.20 \pm 0.08$ & $2.42 \pm 0.06$ & $66.59 \pm 1.37$ & $44.20 \pm 0.78$ \\
CV & 3.34 & 2.04 & 2.74 & 2.54 & 2.50 & 1.79 \\
$F$ & 2.08 & 38.69 & 136.53 & 25.04 & 13.68 & 218.33 \\
$P$ & 0.2115 & 0.0019 & 0.0002 & 0.0043 & 0.0133 & 0.0001 \\
\hline
\end{tabular}

${ }^{\mathrm{a}, \mathrm{b}}$ Values in the same column with different superscripts differ significantly at $P<0.05$.

TABLE 2: Mean of larvae and cocoon traits of a silkworm hybrid fed with three varieties of mulberry leaves.

\begin{tabular}{|c|c|c|c|c|c|c|}
\hline $\begin{array}{l}\text { Tree } \\
\text { variety }\end{array}$ & Larvae $(g)$ & Mortality (\%) & Cocoon $(g)$ & Number of cocoon (per liter) & $\begin{array}{l}\text { Weight of a litter of } \\
\text { cocoon }(\mathrm{g})\end{array}$ & $\begin{array}{c}\text { Best cocoon weight per } \\
1000 \text { larvae }(\mathrm{kg})\end{array}$ \\
\hline Kenmochi & 1.62 & 4.33 & 0.63 & 112.67 & 181.63 & $1.521^{\mathrm{a}}$ \\
\hline Native & 1.59 & 10.00 & 0.64 & 111.00 & 176.31 & $1.361^{\mathrm{ab}}$ \\
\hline $\begin{array}{l}\text { Black } \\
\text { berry }\end{array}$ & 1.51 & 11.33 & 0.61 & 119.67 & 181.06 & $1.267^{\mathrm{b}}$ \\
\hline $\mathrm{CV}$ & 4.47 & 49.28 & 4.44 & 4.19 & 5.83 & 6.02 \\
\hline Mean \pm SE & $1.58 \pm 0.83$ & $8.56 \pm 4.22$ & $0.63 \pm 0.03$ & $114.44 \pm 4.79$ & $179.67 \pm 10.47$ & $1.38 \pm 0.83$ \\
\hline$F$ & 1.82 & 1.67 & 1.85 & 1.53 & 0.46 & 3.57 \\
\hline$P$ & 0.2882 & 0.3148 & 0.2836 & 0.3451 & 0.7659 & 0.1226 \\
\hline
\end{tabular}

${ }^{\mathrm{a}, \mathrm{b}}$ Values in the same column with different superscripts differ significantly at $P<0.05$.

TABLE 3: Mean of shell parameters and some of the nutritional indices of silkworm hybrid treated with three varieties of mulberry leaves.

\begin{tabular}{|c|c|c|c|c|c|c|}
\hline Tree variety & Shell weight (g) & Shell percentage & Shell ECI (\%) & Shell ECD (\%) & Cocoon ECD (g) & Cocoon ECI (g) \\
\hline Kenmochi & 0.41 & $25.23^{\mathrm{a}}$ & $9.02^{\mathrm{a}}$ & 16.46 & 26.08 & $14.29^{\mathrm{a}}$ \\
\hline Native & 0.41 & $25.91^{\mathrm{a}}$ & $7.66^{\mathrm{b}}$ & 19.03 & 29.38 & $11.82^{\mathrm{b}}$ \\
\hline Black berry & 0.36 & $23.89^{\mathrm{b}}$ & $6.54^{\mathrm{b}}$ & 17.67 & 29.57 & $10.94^{\mathrm{b}}$ \\
\hline $\mathrm{CV}$ & 6.67 & 2.20 & 7.68 & 7.49 & 5.74 & 5.30 \\
\hline Mean \pm SE & $0.39 \pm 0.03$ & $25.01 \pm 0.55$ & $7.74 \pm 0.59$ & $17.72 \pm 1.33$ & $28.34 \pm 0.65$ & $12.35 \pm 0.65$ \\
\hline$F$ & 2.00 & 5.90 & 6.93 & 1.82 & 3.12 & 11.37 \\
\hline$P$ & 0.2593 & 0.057 & 0.0437 & 0.2888 & 0.1479 & 0.0186 \\
\hline
\end{tabular}

${ }^{\mathrm{a}, \mathrm{b}}$ Values in the same column with different superscripts differ significantly at $P<0.05$.

performance traits; therefore this variety can be recommended for rearing silkworm in the Torbat Heydarieh region.

\section{Data Availability}

All data used to support the findings of this study are available from the corresponding author upon request.

\section{Conflicts of Interest}

The authors declare that they have no conflicts of interest.

\section{Acknowledgments}

This research was financially supported by the Research Deputy of Education and Research, University of Torbat Heydarieh (Grant 1086).

\section{References}

[1] N. Kumari and S. P. Roy, "Some aspects of the identification of nutritionally efficient silkworms (Insecta: Lepidoptera:
Bombycoidea), their metabolic rate and sustainable development as energy resources," The Bioscan, vol. 6, no. 3, pp. 475-481, 2011.

[2] Sericulture Development Center of Iran, in Rasht, "Statisticalyear book," in Persian, 2017, http://noghan.maj.ir.

[3] FAO (Food and Agricultural Organization), "FAOSTAT data BASE," 2018, http://www.fao.org/faostat/en/\#data/QL.

[4] C. Vanitha and K. C. Narayanaswamy, "Performance of silkworm on tree mulberry, Morus alba L," International Journal of Current Microbiology and Applied Sciences, vol. 8, no. 04, pp. 2020-2025, 2019.

[5] R. Lalfelpuii, B. N. Choudhury, G. Gurusubramanian, and N. S. Kumar, "Effect of different mulberry plant varieties on growth and economic parameters of the silkworm Bombyx mori in Mizoram," Scince Vision, vol. 14, no. 1, pp. 34-38, 2014.

[6] P. D. Sadaphal, C. B. Latpate, and T. A. Nikam, "Performance of biovoltine silkworm hybrid on different mulberry cultures under reainfed conditions," in Proceedings of National Conference on Harmony with Nature in Context of Bioresources and Environmental Health (HORMONY-2015), pp. 173-176, Aurangabad. India, November 2015.

[7] L. Andadari, M. Minarningsih, and R. Dewi, "The effect of mulberry types on the productivity of cocoon of two Bombyx 
mori L silkworm hybrids," Widyariset, vol. 3, no. 2, pp. 119-130, 2017.

[8] M. H. Hosseini, Principals of Silkworm Breeding, University of Guilan, Rasht, Iran, in Persian, 2005.

[9] E. Muniraju, B. M. Shekharappa, and R. Raghuraman, "Relation among food consumption, conversion and cocoon production in silkworm، Bombyx mori reared at different temperatures," International Journal of Industerial Entomology, vol. 7, no. 2, pp. 203-208, 2003.

[10] K. V. Rahmathulla, T. M. Himantharaj, G. Srinivasa, and K. R. Rajan, "Association of moisture content in mulberry leaf with nutritional parameters of bivoltine silkworm (Bombyx mori L.). Kun chong xue bao," Acta Entomologica Sinica, vol. 47, no. 6, pp. 701-704, 2004.

[11] D. C. Paul, G. Subba Rao, and D. C. Deb, "Impact of dietary moisture on nutritional indices and growth of Bombyx mori and concommitant larval duration," Journal of Insect Physiology, vol. 38, no. 3, pp. 229-235, 1992.

[12] H. Motahari, M. Rezaei, and A. R. Seidavi, "Effects of different mulberry leaves on the performance of silkworm in Mazandaran province," Journal of Iraninan Animal Science, vol. 40, no. 3, pp. 49-58, 2009.

[13] G. S. Rajanna and G. S. Reddy, "Studies on the variability and interrelationship between some quantitative characters in different breeds of silkworm, Bombyx mori L." Journal of Sericulture, vol. 30, no. 1, pp. 673-677, 1990.

[14] K. Etebari, R. Ebadi, and M. Fazilati, "Nutritional effects of two different mulberry varieties on the economic, biologic and biochemical properties of silkworm Bombyx mori L. in Esfahan Province," Agriculture and Natural Resources Science, vol. 12, pp. 17-26, 2005.

[15] R. Radjabi Kanafgourabi, R. Ebadi, S. Mirhosseini, and A. Seidavi, "Feeding effects of two mulberry varieties on some biological parameters and economical characters of silkworm Bombyx mori L," Agriculture Research, vol. 8, no. 3, pp. 1-8, 2008.

[16] T. C. Fonseca, J. E. Almeida, and A. S. Fonseca, "Effect of mulberry selection on silkworm feeding," Journal of Sericologia, vol. 30, no. 4, pp. 475-477, 1990.

[17] A. R. Bizhannia and A. R. Seidavi, Principal and Techniques of Silkworm Breeding, Haghshenass publication, Rasht, Iran, p. 131, 2008.

[18] B. K. Das, J. Saker, C. Das, N. K. Das, and S. K. Sen, “Seasonal effects on the relative performance of five bivoltine breeds of silkworm B. mori," Journal of Zoology, vol. 15, no. 2, pp. 91-96, 1995.

[19] S. Satake, Y. Kawabe, and A. Mizoguchi, "Carbohydrate metabolism during starvation in the silkworm Bombyx mori L." Archives of Insect Biochemistry and Physiology, vol. 44, no. 2, pp. 90-98, 2000.

[20] R. Samami, A. Seidavi, N. Eila et al., "Production performance and economic traits of silkworms (Bombyx mori L., 1758) fed with Mulberry tree leaves (Morus alba, var. Ichinose) significantly differ according to hybrid lines," Livestock Science, vol. 226, pp. 133-137, 2019. 